\title{
Draft genome sequences of three fungal-interactive Paraburkholderia terrae strains, BS007, BS110 and BS437
}

\author{
Akbar Adjie Pratama1*(D, Irshad UI Haq ${ }^{1}$, Rashid Nazir², Maryam Chaib De Mares ${ }^{1}$ and Jan Dirk van Elsas ${ }^{1 *}$
}

\begin{abstract}
Here, we report the draft genome sequences of three fungal-interactive Paraburkholderia terrae strains, denoted BS110, BS007 and BS437. Phylogenetic analyses showed that the three strains belong to clade II of the genus Burkholderia, which was recently renamed Paraburkholderia. This novel genus primarily contains environmental species, encompassing non-pathogenic plant- as well as fungal-interactive species. The genome of strain BS007 consists of 11,025,273 bp, whereas those of strains BS110 and BS437 have 11,178,081 and 11,303,071 bp, respectively. Analyses of the three annotated genomes revealed the presence of (1) a large suite of substrate capture systems, and (2) a suite of genetic systems required for adaptation to microenvironments in soil and the mycosphere. Thus, genes encoding traits that potentially confer fungal interactivity were found, such as type 4 pili, type 1, 2, 3, 4 and 6 secretion systems, and biofilm formation (PGA, alginate and pel) and glycerol uptake systems. Furthermore, the three genomes also revealed the presence of a highly conserved five-gene cluster that had previously been shown to be upregulated upon contact with fungal hyphae. Moreover, a considerable number of prophage-like and CRISPR spacer sequences was found, next to genetic systems responsible for secondary metabolite production. Overall, the three $P$. terrae strains possess the genetic repertoire necessary for adaptation to diverse soil niches, including those influenced by soil fungi.
\end{abstract}

Keywords: Paraburkholderia terrae, Mycosphere, Fungal-interactive, Genome

\section{Introduction}

The genus Burkholderia was proposed in 1993 by Yabuuchi et al. [1]. Following this, continuing emendation of the genus has occurred, mainly as a result of the addition of new species. Recent molecular and phylogenetic analysis of the genus divided it into two clades, with clade I containing the pathogenic Burkholderia spp. and clade II mainly environmental bacteria. The latter clade was reclassified as a novel genus, named Paraburkholderia [2, 3]. This genus encompasses a suite of highly diverse and environmentally adaptable bacteria that are able to occupy various ecological niches, ranging from soil $[4,5]$ to plants and humans [6]. Members of the genus Paraburkholderia are also known to

\footnotetext{
* Correspondence: A.A.P.Pratama@rug.nl; j.d.van.elsas@rug.nl 1Department of Microbial Ecology, Microbial Ecology - Groningen Institute for Evolutionary Life Sciences, University of Groningen, Nijenborgh 7 , Groningen 9747, AG, The Netherlands

Full list of author information is available at the end of the article
}

harbor some of the largest genomes among all known bacteria $[7,8]$.

Paraburkholderia terrae strain BS001, which was isolated as a co-migrator in soil with the saprotrophic fungus Lyophyllum sp. strain Karsten [9], has been extensively described, and it is used here as a reference organism. $P$. terrae strain BS110 was isolated from the mycosphere of the ecotomycorrhizal fungus Laccaria proxima [5, 9] and also showed comigration capacity with the aforementioned fungus. The other two Paraburkholderia terrae strains (BS007, BS437) were isolated - similarly - as mycosphere dweller / comigrator, from soils collected in Gieterveen and Wageningen, the Netherlands, respectively $[5,9]$. Being avid mycosphere inhabitants, all these Paraburkholderia strains might play essential roles in the ecology of soil fungi and so in (degradative) ecosystem functions. Several studies have been performed to address such interactions and understand the mechanisms involved. An in-depth study of the genome of $P$. terrae strain BS001 revealed its remarkable genetic 
potential, including genetic systems that presumably enable it to interact with saprotrophic fungi like Lyophyllum sp. strain Karsten [5, 8]. Moreover, the strain BS001 genome was found to contain numerous regions of genomic plasticity that are typified by different plasmid- and prophage-like genes [8]. We took this finding as a token of the remarkable ability of $P$. terrae to adapt - via horizontal gene transfer to fluctuating local challenges, including the presence of fungal counterparts. The strategies that are presumably used in this fungal interactivity include (but are not limited to): (i) biofilm formation on fungal surfaces $[9,10]$, (ii) a type-3 secretion system (T3SS) with a subtle role in the cellular migration along fungal hyphae and adherence $[10,11]$ and (iii) chemotaxis towards growing fungal hyphae and subsequent adherence to fungal surfaces [10]. In a recent study, it was shown that $P$. terrae strain BS001 differentially expresses genes involved in chemotaxis, flagellar motility and metabolic and stress response mechanisms in response to fungal hyphae [12].

Given the fact that the three novel $P$. terrae strains BS110, BS437 and BS007 were isolated by virtue of their capacity to interact with soil fungi, we hypothesized that their physiological responses to fungi, as reflected in their genomic make-up, might be similar across them and akin to those of the well-studied strain BS001. To further explore this tenet, analyses of sequenced genomes constitute a necessary first step. Here, we present a summary of the draft genome sequences, and their annotation, of the three novel $P$. terrae strains. Furthermore, we examine the traits that allow to build hypotheses with respect to the ecological relevance of these strains in the mycosphere, coupled to analyses of phenotypes. Based on these characteristics, we thus shed light on the potential strategies that these strains may use in the interplay with their fungal counterparts.

\section{Organism information}

\section{Classification and features}

P. terrae BS110 and BS007 were isolated from the base of fruiting bodies of the ectomycorrhizal fungus Laccaria proxima, sampled in Gieterveen, the Netherlands [9]. Like the reference strain BS001, strain BS437 was isolated as a comigrator with $L$. sp strain Karsten (in this case it was isolated from soil from Droevendaal, Wageningen, the Netherlands). The collected samples were treated as previously described $[5,9]$. Briefly, for isolation of $P$. terrae BS110 and BS007, mycosphere samples were carefully collected from soil adhering to the dense L. proxima hyphae just below the fruiting body. Strains BS001 and BS437 were isolated as 'winners' of microbiome co-migration experiments [5, 9]. All isolated Paraburkholderia strains were grown on LB medium at $28{ }^{\circ} \mathrm{C}$. Phylogenetic analyses based on alignment of seven concatenated core genome genes (aroE, dnaE, groeL, gyrB, mutL, recA, and rpoB) (Fig. 1) showed that $P$. terrae strains BS110, BS007 and BS437 clustered within the Paraburkholderia genus (akin to the former Burkholderia clade II), as reported previously for strain BS001 [8]. Based on these analyses, our four P. terrae strains were also found to be closely related to Paraburkholderia phytofirmans and P. xenovorans.

Gram staining of freshly-grown cells of $P$. terrae strains BS007, BS110 and BS437 revealed all three strains to be Gram-negative. Transmission electron microscopy of freshly-grown cultures showed that each strain population consisted mainly of single cells that were rod-shaped (cell lengths 1 to $2 \mu \mathrm{m}$ ), with predominantly polar flagella (Fig. 2).

The growth of all strains was tested at different temperatures $\left(4,12,15,18,24,37,42\right.$ and $\left.50{ }^{\circ} \mathrm{C}\right)$. For all strains, the temperature range that allowed the formation of detectable CFUs on plates was $15-37{ }^{\circ} \mathrm{C}$, with optimum growth being recorded at $28{ }^{\circ} \mathrm{C}$ within 3 days. The $\mathrm{pH}$ tolerance of strains was tested by assessing the growth of colonies of each of the strains on R2A plates under different $\mathrm{pH}$ (specifically 4.0, 5.0, 6.0, 7.0, 8.0, 9.0 and 10.0) at $28{ }^{\circ} \mathrm{C}$. All strains were able to grow in the $\mathrm{pH}$ range 5.0 10.0, with optimum growth at $\mathrm{pH}$ 6.0-7.0. No growth was recorded at $\mathrm{pH}$ 4.0. Salt tolerance assays were done by placing cells on R2A plates supplemented with different $\mathrm{NaCl}$ concentrations (specifically zero, 0.5, 1.0, 2.0, 2.5, 5.0 and $10 \%)$, and incubating for up to five days, with regular observation of colony formation. Strains BS007, BS110 and BS437 were able to grow at up to $1 \% \mathrm{NaCl}$ in the $\mathrm{R} 2 \mathrm{~A}$ medium, being strongly inhibited at $2 \% \mathrm{NaCl}$. Hence, all three strains tested are quite salt-sensitive.

The capacities of the strains to utilize an array of carbon sources were tested using BIOLOG GN2 assays (Biolog Inc., Hayward, CA). The results revealed that most strains are able to utilize a suite of different carbonaceous compounds (Tables 1, 2, and 3) (as in Nazir et al. [5]). Some of the carbonaceous compounds could only be utilized by some, but not all, strains. That is, strains BS007 and BS110 (but not BS437) could utilize d-trehalose, phenyl ethylamine, 2,3-butanediol and gentiobiose. The compound dcellobiose was utilized only by strains BS007 and BS437, while $\gamma$-hydroxybutyric acid was utilized only by strains BS110 and BS437. There was also substrate specificity, in that some compounds could only be utilized by one strain each. For instance, strain BS007 utilized itaconic acid, whereas $\mathrm{d}$-serine and $\alpha$-d-lactose were uniquely utilized by strain BS110, and d-melibiose, $\beta$-methyl-d-glucoside and $\alpha$ ketoglutaric acid by strain BS437.

\section{Genome sequencing information Genome project history}

P. terrae BS110 and BS007 were isolated from the base of fruiting bodies of Laccaria proxima, in Gieterveen, the Netherlands and strain BS437 was isolated - as a comigrator with L. sp strain Karsten - from Droevendaal, 

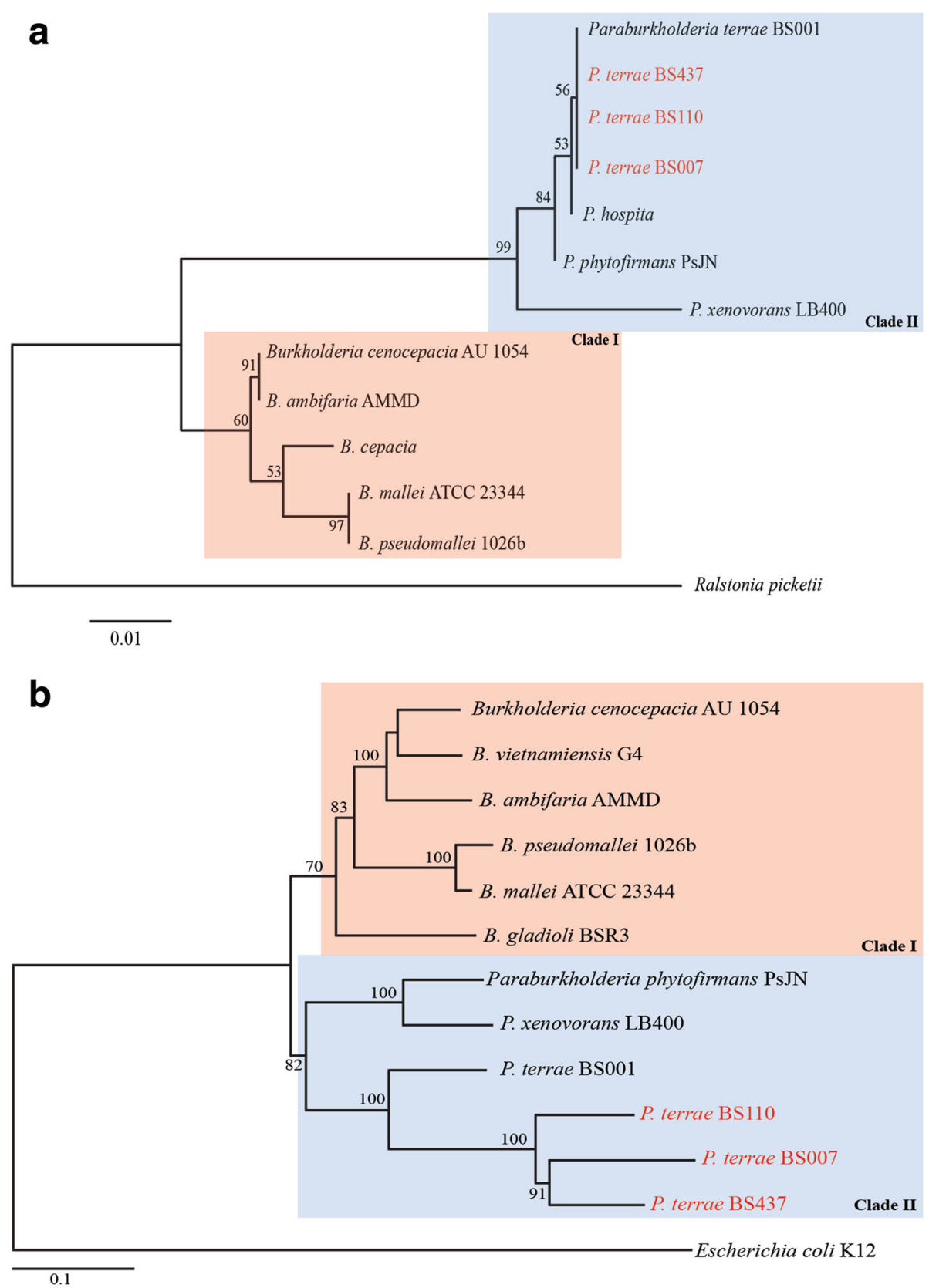

Fig. 1 Phylogenetic tree of selected Burkholderiaand Paraburkholderia strains based on 165 rRNA gene sequences (a) and on alignment of seven concatenated core genes ( $a r o E$, dnaE, groeL, gyrB, mutL, recA, and rpoB) (b). Evolutionary distance were computed with MEGA7 using the maximumlikelihood method. The bootstrap values above 50\% (from 1000 replicates) are indicated at the nodes. P. terrae strains BS007, BS110 and BS437 were all found to belong to clade II. Clade I mainly consists of pathogenic Burkholderiaspecies, while clade II, mainly consisting of environmental strains, was assigned to the new genus Paraburkholderia. See Sawana et al. [3]

Wageningen, The Netherlands. The three strains were selected for sequencing, as they showed migration proficiency in soil along with the fungus Lyophyllum sp. strain Karsten, similar to the closely related $P$. terrae strain BS001 [5]. Moreover, there is a current lack of knowledge on the mechanisms behind the behavior of such fungal-interactive
P. terrae strains. Sequencing of the draft genomes was completed in 2012, and the sequences of strain BS007, BS110 and BS437 have been deposited for public release at NCBI under the accession numbers NFVE00000000, NFVD00000000 and NFVC00000000, respectively. A summary of the project information is shown in Table 4. 

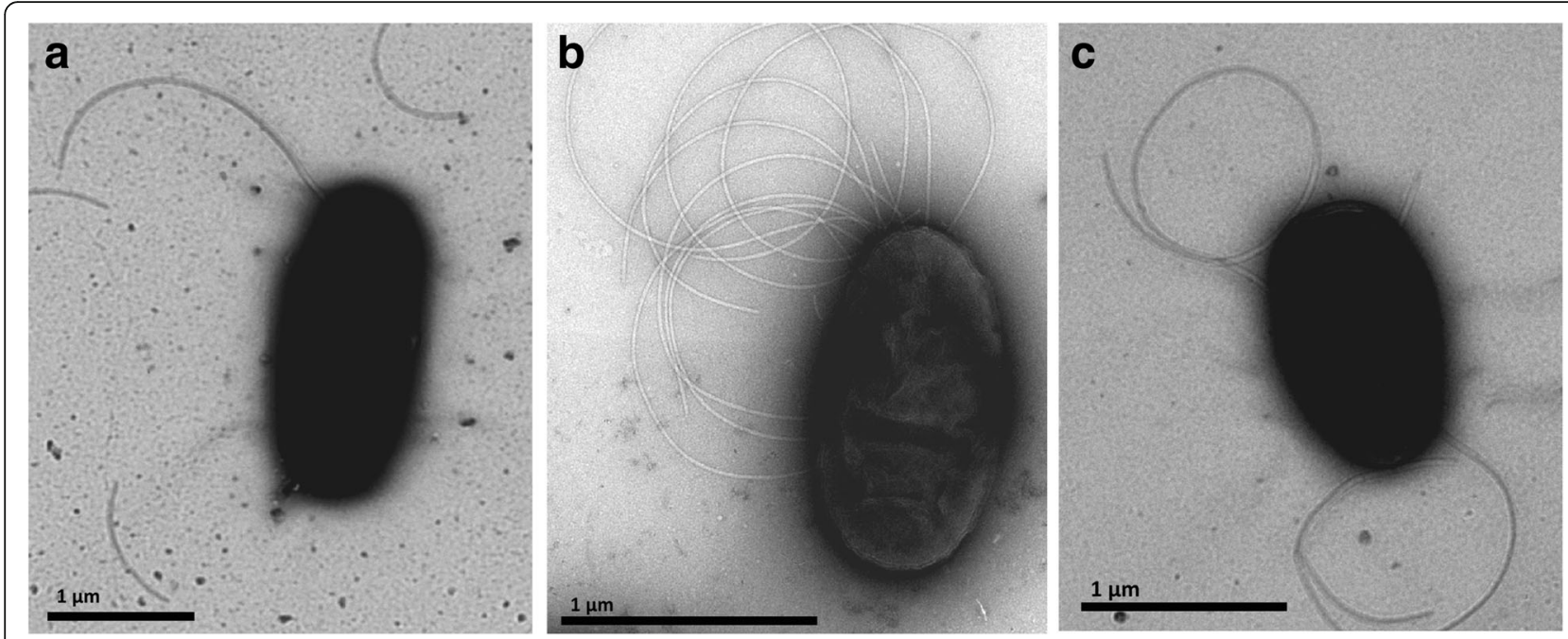

Fig. 2 Transmission electron microscopy of (a) Paraburkholderia terrae strain BS110, (b) P. terrae strain BS007, and (c) P. terrae strain BS437. The scale bars represent $1 \mu \mathrm{m}$

\section{Growth conditions and genomic DNA preparation}

All strains were grown aerobically on LB medium at $28^{\circ} \mathrm{C}$ (180 rpm, shaking, overnight). The genomic DNA of the overnight cultures was then extracted using a modified (Powersoil) DNA isolation kit (MOBio Laboratories Inc., Carlsbad, CA, USA). The modification consisted of adding glass beads to the cultures to spur mechanical cell lysis. This extraction method is a rapid way to produce highly pure DNA from bacterial cultures. The extracted gDNAs were purified with the Wizard DNA cleanup system (Promega, Madison, USA). The quality and quantity of the extracted DNAs were assessed using electrophoresis in $1 \%$ agarose.

\section{Genome sequencing and assembly}

The genomic DNAs of P. terrae strains BS110, BS007 and BS437 were sequenced on the Illumina HiSeq2000 platform by LCG Genomics (Berlin, Germany). The libraries for the strains were prepared using Illumina TruSeq libraries with Covaris-sheared DNA or TruSeq ${ }^{\circ}$ Nano DNA Library Prep. Totals of approximately 18, 16 and 17 million paired reads were produced for the P. terrae BS007, BS110 and BS437 strains, respectively. Illumina's CASAVA data analysis software was used for further processing, such as adapter trimming and quality trimming using the fast $\mathrm{X}$ toolkit. K-mer error correction analysis was done using Quake Version 0.3; the K-mer corrected paired reads were 16, 15 and 15 million for BS007, BS110 and BS437. Genome assembly was then carried out using Velvet version 1.2.05, by LCG Genomics (statistics of the sequencing is provided in Additional file 1: Table S1). Totals of 788, 658 and 843 contigs were formed following assembly, for strains BS007, BS110 and BS437, respectively.
The 16S rRNA genes were extracted and added as a separate scaffold. The extraction of $16 \mathrm{~S}$ rRNA genes was done using SortMeRNA and assembly using SPAdes version 3.9.0.

\section{Genome annotation}

The sequence information of the P. terrae BS007, BS110 and BS437 genomes was submitted to the MicroScope platform that is hosted at Genoscope [13] for analysis. The gene annotation editor in MicroScope was used; it includes the use of TrEMBL, SwissProt alignments, the PubMed and InterPro databases and SignalP. The MicroScope platform is also integrated with a metabolic profiling platform that includes the PkGDB database, as well as MicroCyc that is designed to extract genomic and metabolic data from the Pathway Genome Databases, KEGG and the secondary metabolite detection program antiSMASH [13].

\section{Genomic properties}

The genome of strain BS007 has an estimated size of $11,025,273 \mathrm{bp}$, with $61.89 \% \mathrm{G}+\mathrm{C}$ content, that of strain BS110 11,178,081 bp $(61.84 \% \mathrm{G}+\mathrm{C})$, and that of strain BS437 11,303,071 bp $(61.84 \% \mathrm{G}+\mathrm{C})$ (Fig. 3). The three genomes contain 10,411 (86.83\%), 10,288 (85.85\%) and $10,610(86.03 \%)$ protein-encoding regions, respectively. The properties and statistics of the genomes are summarized in Table 5, and the numbers of genes associated with general COG functional categories in Table 6 .

Comparative genomics based analyses of the pan and core genomes of strains BS007, BS110 and BS437 revealed that these - across the three strains - comprised 17,404 coding regions, whereas the core genome 
Table 1 Classification and general features of Paraburkholderia terrae strain BS110 [26]

\begin{tabular}{|c|c|c|c|}
\hline MIGS ID & Property & Term & Evidence code $^{a}$ \\
\hline & & Domain: Bacteria & TAS [27] \\
\hline & & Phylum: Proteobacteria & TAS [28] \\
\hline & & Class: Betaproteobacteria & TAS [29] \\
\hline & & Order: Burkholderiales & TAS [30] \\
\hline & & Family: Burkholderiaceae & TAS [31] \\
\hline & & Genus: Paraburkholderia & TAS $[3,32]$ \\
\hline & & Species: Paraburkholderia terrae & TAS $[3,32]$ \\
\hline & & Strain: BS110 & TAS [5] \\
\hline & Gram-stain & Negative & IDA, TAS $[5,32]$ \\
\hline & Cell shape & Rod-shaped & IDA, TAS $[5,32]$ \\
\hline & Motility & Motile & TAS $[5,32]$ \\
\hline & Sporulation & Not reported & \\
\hline & Temperature range & $15^{\circ} \mathrm{C}-37^{\circ} \mathrm{C}$ & TAS [5] \\
\hline & Optimum temperature & $28^{\circ} \mathrm{C}$ & TAS [5] \\
\hline & pH range; Optimum & $5.0-10.0 ; 6.0-7.0$ & TAS [5] \\
\hline & Carbon source & $\begin{array}{l}\text { Tween40, tween80, I-fucose, gentiobiose, a-d-lactose, lactulose, } \\
\text { d-psicose, d-trehalose, xylitol, succinic acid monomethyl ester, } \\
\text { Y- hydroxybutyric acid, itaconic acid, a-ketovaleric acid, } \\
\text { succinamic acid, glucuronamide, I-alaninamide, d-alanine, } \\
\text { I-ornithine, d-serine, d,l-carnitine, urocanic acid, phenylethyl-amine, } \\
\text { 2,3-butanediol, d,l, a- glycerol phosphate, d-glucose-6-phosphate }\end{array}$ & TAS [5] \\
\hline MIGS-6 & Habitat & Soil, mycosphere & TAS $[5,32]$ \\
\hline MIGS-6.3 & Salinity & $1 \% \mathrm{NaCl}$ & TAS [5] \\
\hline MIGS-22 & Oxygen requirement & Aerobic & TAS [5] \\
\hline MIGS-15 & Biotic relationship & Soil microbe, free living & TAS [5] \\
\hline \multirow[t]{2}{*}{ MIGS-14 } & Pathogenicity & Non pathogen & TAS [5] \\
\hline & Biosafety level & Non pathogen & TAS [5] \\
\hline MIGS-15 & Geographic location & Gieterveen, Netherlands & TAS [5] \\
\hline MIGS-5 & Sample collection & 2012 & TAS [5] \\
\hline MIGS-4.1 & Latitude & $53^{\circ} \mathrm{N}$ & TAS [5] \\
\hline MIGS-4.2 & Longitude & $6^{\circ} \mathrm{E}$ & TAS [5] \\
\hline
\end{tabular}

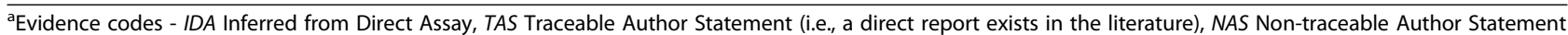
(i.e., not directly observed for the living, isolated sample, but based on a generally accepted property for the species, or anecdotal evidence). These evidence codes are from the Gene Ontology project. If the evidence is IDA, then the property was directly observed for a live isolate by one of the authors or an expert mentioned in the acknowledgement

contained only 8520 such regions. The variable genome thus contained 8884 coding regions. The analysis further showed that the three strains contain $15.79 \%, 16.26 \%$ and $22.75 \%$ strain-specific coding regions, respectively (Fig. 4; Additional file 1: Table S2).

\section{Insights into the genome sequences}

Each of the genomes of P. terrae strains BS007, BS110 and BS437 was found to contain genes predicted to encode highly diverse primary and secondary metabolisms, as previously found in strain BS001 [8]. For example, numerous sets of genes were predicted to be involved in carbohydrate metabolism (Additional file 1: Table S3). Also, genes for predicted uptake systems were abundantly present across the three strains. Remarkably, the glycerol uptake and glycerol kinase genes $g l p K$ and $g l p D$ were found consistently across all three strains. These genes had 100\% homology with the same genes found in strain BS001. Secondary metabolite analyses showed that the three strains contain 14, 16 and 17 gene clusters encoding these (strain BS007, BS110 and BS437, respectively; Additional file 1: Table S4). In each strain, one gene cluster was found for nonribosomal peptide synthetase (NRPS) and a hybrid NRPS and polyketide synthase (PKS). Remarkably, the NRPS-PKS encoding systems of strains BS007 and BS110 had the same length (12,267 bp) as well as peptide monomer composition (val-mal-gly). In contrast, the strain BS437 system was shorter (length 9398 bp) and had a reduced peptide 
Table 2 Classification and general features of Paraburkholderia terrae strain BS007 [26]

\begin{tabular}{|c|c|c|c|}
\hline MIGS ID & Property & Term & Evidence code $^{a}$ \\
\hline & & Domain: Bacteria & TAS [27] \\
\hline & & Phylum: Proteobacteria & TAS [28] \\
\hline & & Class: Betaproteobacteria & TAS [29] \\
\hline & & Order: Burkholderiales & TAS [30] \\
\hline & & Family: Burkholderiaceae & TAS [31] \\
\hline & & Genus: Paraburkholderia & TAS $[3,32]$ \\
\hline & & Species: Paraburkholderia terrae & TAS $[3,32]$ \\
\hline & & Strain: BS007 & TAS [5] \\
\hline & Gram-stain & Negative & IDA, TAS $[5,32]$ \\
\hline & Cell shape & Rod-shaped & IDA, TAS $[5,32]$ \\
\hline & Motility & Motile & TAS $[5,32]$ \\
\hline & Sporulation & Not reported & \\
\hline & Temperature range & $15^{\circ} \mathrm{C}-37^{\circ} \mathrm{C}$ & TAS [5] \\
\hline \multirow[t]{3}{*}{ MIGS } & Optimum temperature & $28^{\circ} \mathrm{C}$ & TAS [5] \\
\hline & pH range; Optimum & $5.0-10.0 ; 6.0-7.0$ & TAS [5] \\
\hline & Carbon source & $\begin{array}{l}\text { Tween40, tween80, d-cellobiose, I-fucose, gentiobiose, } \\
\text { lactulose, d-psicose, d-trehalose, xylitol, succinic acid } \\
\text { monomethyl ester, itaconic acid, a-ketovaleric acid, } \\
\text { succinamic acid, glucuronamide, l-alaninamide, d-alanine, } \\
\text { l-ornithine, d,l-carnitine, urocanic acid, phenylethyl-amine, } \\
\text { 2,3-butanediol, d,l, a- glycerol phosphate, d-glucose-6-phosphate }\end{array}$ & TAS [5] \\
\hline MIGS-6 & Habitat & Soil, mycosphere & TAS $[5,32]$ \\
\hline MIGS-6.3 & Salinity & $1 \% \mathrm{NaCl}$ & TAS [5] \\
\hline MIGS-22 & Oxygen requirement & Aerobic & TAS [5] \\
\hline MIGS-15 & Biotic relationship & Soil microbe, free living & TAS [5] \\
\hline \multirow[t]{2}{*}{ MIGS-14 } & Pathogenicity & Non pathogen & TAS [5] \\
\hline & Biosafety level & Non pathogen & TAS [5] \\
\hline MIGS-15 & Geographic location & Gieterveen, Netherlands & TAS [5] \\
\hline MIGS-5 & Sample collection & 2012 & TAS [5] \\
\hline MIGS-4.1 & Latitude & $53^{\circ} \mathrm{N}$ & TAS [5] \\
\hline MIGS-4.2 & Longitude & $6^{\circ} \mathrm{E}$ & TAS [5] \\
\hline
\end{tabular}

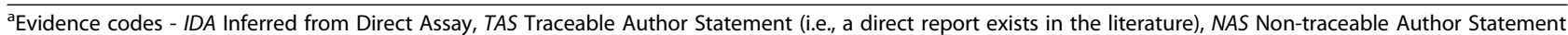
(i.e., not directly observed for the living, isolated sample, but based on a generally accepted property for the species, or anecdotal evidence). These evidence codes are from the Gene Ontology project. If the evidence is IDA, then the property was directly observed for a live isolate by one of the authors or an expert mentioned in the acknowledgement

monomer composition (mal-gly). Remarkable, we found an additional NRPS gene cluster, uniquely, in the genome of strain BS110 (Additional file 1: Table S4). Next to these gene clusters, others encoding bacteriocin, terpene, ectoine, phosphonate and aryl polene production were also found in all three strains (Additional file 1: Table S4).

In addition, sets of plant-interactive genes were detected in all three genomes. In particular, those for production of indole acetic acid from tryptophan, as well as of 1aminocyclopropane-1-carboxylate deaminase (ACC deaminase), were found. We also found the nodulation genes $\operatorname{nodI}, \operatorname{nod} J, \operatorname{nod} N$ and $\operatorname{nod} W$ across all three genomes, next to (uniquely) nodV in strain BS110 (Additional file 1: Table S5). Similar sets of genes have previously been found in strain BS001 and these were implied in a putative 'rhizosphere phase' of this strain [8]. Together, the data indicated the presence of genes for a convergent suite of traits with ecological relevance across the three strains.

With respect to fungal interactivity, the bacterial type- 4 pilus system might be involved [14]. In Pseudomonas aeruginosa, type- 4 pili are required for microbial motility as well as biofilm adherence [15]. In our three strains, we found complete sets of type-4 pili genes, named pilA, pilB, pilC, pilD, pilF, pilM, pilN, pilO/pilP, pilQ, pilT and fimT (Table 7). This gene constellation is, however, different from that of strain BS001, which apparently lost its pilP gene [14].

The ability of bacteria to produce exopolysaccharides is critical in biofilm formation, and the biofilm (extra-matrix) 
Table 3 Classification and general features of Paraburkholderia terrae strain BS437 [26]

\begin{tabular}{|c|c|c|c|}
\hline MIGS ID & Property & Term & Evidence code $^{a}$ \\
\hline & & Domain: Bacteria & TAS [27] \\
\hline & & Phylum: Proteobacteria & TAS [28] \\
\hline & & Class: Betaproteobacteria & TAS [29] \\
\hline & & Order: Burkholderiales & TAS [30] \\
\hline & & Family: Burkholderiaceae & TAS [31] \\
\hline & & Genus: Paraburkholderia & TAS $[3,32]$ \\
\hline & & Species: Paraburkholderia terrae & TAS $[3,32]$ \\
\hline & & Strain: BS437 & TAS [5] \\
\hline & Gram-stain & Negative & IDA, TAS $[5,32]$ \\
\hline & Cell shape & Rod-shaped & IDA, TAS $[5,32]$ \\
\hline & Motility & Motile & TAS $[5,32]$ \\
\hline & Sporulation & Not reported & \\
\hline & Temperature range & $15^{\circ} \mathrm{C}-37^{\circ} \mathrm{C}$ & TAS [5] \\
\hline & Optimum temperature & $28^{\circ} \mathrm{C}$ & TAS [5] \\
\hline & pH range; Optimum & $5.0-10.0 ; 6.0-7.0$ & TAS [5] \\
\hline & Carbon source & $\begin{array}{l}\text { Tween40, tween80, d-cellobiose, I-fucose, a-d-lactose, } \\
\text { lactulose, d-melibiose, } \beta \text {-methyl-d-glucoside, d-psicose, } \\
\text { xylitol, succinic acid monomethyl ester, } \gamma \text { - hydroxybutyric acid, } \\
\text { a-ketoglutaric acid, a-ketovaleric acid, succinamic acid, } \\
\text { glucuronamide, l-alaninamide, d-alanine, l-ornithine, } \\
\text { d,l-carnitine, urocanic acid, 2,3-butanediol, d,l, a- glycerol } \\
\text { phosphate, d-glucose-6-phosphate }\end{array}$ & TAS [5] \\
\hline MIGS-6 & Habitat & Soil, mycosphere & TAS $[5,32]$ \\
\hline MIGS-6.3 & Salinity & $1 \% \mathrm{NaCl}$ & TAS [5] \\
\hline MIGS-22 & Oxygen requirement & Aerobic & TAS [5] \\
\hline MIGS-15 & Biotic relationship & Soil microbe, free living & TAS [5] \\
\hline \multirow[t]{2}{*}{ MIGS-14 } & Pathogenicity & Non pathogen & TAS [5] \\
\hline & Biosafety level & Non pathogen & TAS [5] \\
\hline MIGS-15 & Geographic location & Wageningen, Droevendaal, Netherlands & TAS [5] \\
\hline MIGS-5 & Sample collection & 2012 & TAS [5] \\
\hline MIGS-4.1 & Latitude & $52^{\circ} \mathrm{N}$ & TAS [5] \\
\hline MIGS-4.2 & Longitude & $5^{\circ} \mathrm{E}$ & TAS [5] \\
\hline
\end{tabular}

${ }^{a}$ Evidence codes - IDA Inferred from Direct Assay, TAS Traceable Author Statement (i.e., a direct report exists in the literature), NAS Non-traceable Author Statement (i.e., not directly observed for the living, isolated sample, but based on a generally accepted property for the species, or anecdotal evidence). These evidence codes are from the Gene Ontology project. If the evidence is IDA, then the property was directly observed for a live isolate by one of the authors or an expert mentioned in the acknowledgement

poly- $\beta$-1,6-N-acetyl-D-glucosamine (PGA) system has been shown to be an important component of Paraburkholderia biofilms [16]. PGA-encoding genes were previously found in the strain BS001 genome [8]. Other exopolysaccharideproduction systems, such as those for alginate, pel and psl, have been identified in P. aeruginosa [17]. The analysis of the genomes of the three novel strains uncovered several such systems in all strains. Specifically, complete PGA systems ( $p g a A, p g a B, p g a C$ and pgaD), next to two genes of the pel (pelB and pelD) system, were found. In Pseudomonas aeruginosa, the pel (pelA-F) system produces a biofilm matrix, a glucose-rich polysaccharide polymer that has essential structural and protective roles [18]. The analysis also found several alginate production system genes $(a \lg A, a \lg B, \operatorname{alg} C, \operatorname{alg} D, \operatorname{alg} P, \operatorname{alg} U$ and $\operatorname{kin} B)$ in all strains. The exception was $\operatorname{algE1}$, which was only found in the strain BS007 genome. In contrast, we did not find any gene from the psl exopolysaccharide production system (Table 7).

Furthermore, complete sets of T3SS-encoding genes were found in all three genomes (Table 7). A phylogenetic tree based on eight (concatenated) conserved genes (SctS, 
Table 4 Project information

\begin{tabular}{|c|c|c|c|c|}
\hline MIGS ID & Property & Strain BS110 term & Strain BS007 term & Strain BS437 term \\
\hline MIGS 31 & Finishing quality & Draft genome & Draft genome & Draft genome \\
\hline MIGS-28 & Libraries used & Illumina TruSeq libraries & Illumina TruSeq libraries & Illumina TruSeq libraries \\
\hline MIGS 29 & Sequencing platforms & Illumina HiSeq2000 & Illumina HiSeq2000 & Illumina HiSeq2000 \\
\hline MIGS 31.2 & Fold coverage & 200.37 & 224.16 & 241.39 \\
\hline MIGS 30 & Assemblers & Velvet version 1.2.05 & Velvet version 1.2.05 & Velvet version 1.2.05 \\
\hline \multirow[t]{6}{*}{ MIGS 32} & Gene calling method & $\begin{array}{l}\text { MicroScope Genoscope } \\
\text { platform [13] }\end{array}$ & $\begin{array}{l}\text { MicroScope Genoscope } \\
\text { platform [13] }\end{array}$ & $\begin{array}{l}\text { MicroScope Genoscope } \\
\text { platform [13] }\end{array}$ \\
\hline & Locus Tag & BTR & BTI & BTS \\
\hline & Genbank ID & NFVD00000000 & NFVE00000000 & NFVC00000000 \\
\hline & GenBank Date of Release & 24 May 2017 & 24 May 2017 & 24 May 2017 \\
\hline & GOLD ID & Gp0216754 & Gp0216770 & Gp0216771 \\
\hline & BIOPROJECT & PRJNA385388 & PRJNA385388 & PRJNA385388 \\
\hline \multirow[t]{2}{*}{ MIGS 13} & Source Material Identifier & $\begin{array}{l}\text { SAMN06888377 } \\
\text { Paraburkholderia collection of The } \\
\text { Department of Microbial Ecology, } \\
\text { University of Groningen, } \\
\text { Netherlands } \\
\text { (RUGME_B3G4) }\end{array}$ & $\begin{array}{l}\text { SAMN06888376 } \\
\text { Paraburkholderia collection of } \\
\text { The Department of Microbial } \\
\text { Ecology, University of Groningen, } \\
\text { Netherlands (RUGME_B3F6) }\end{array}$ & $\begin{array}{l}\text { SAMN06888378 } \\
\text { Paraburkholderia collection } \\
\text { of The Department of Microbial } \\
\text { Ecology, University of Groningen, } \\
\text { Netherlands (RUGME_B3H4) }\end{array}$ \\
\hline & Project relevance & $\begin{array}{l}\text { Fungi- interactive, phylogenetic } \\
\text { tree, prophage identification. }\end{array}$ & $\begin{array}{l}\text { Fungi- interactive, phylogenetic } \\
\text { tree, prophage identification. }\end{array}$ & $\begin{array}{l}\text { Fungi- interactive, phylogenetic tree } \\
\text { prophage identification. }\end{array}$ \\
\hline
\end{tabular}

SctR, SctQ, SctV, SctU, Sct), SctN and SctT) of the T3SS showed that all systems belong to the Hrp-2 type of the T3SS (Figs. 5 and 6). It has been suggested that this type is required for the establishment of interaction with fungi $[19,20]$. Moreover, copies (sometimes partial) of other secretion systems, i.e. the T1SS, T2SS, T4SS and T6SS, were discovered in the three genomes (Additional file 1: Table S6). These genomic evidences indicate that the three $P$. terrae strains are highly versatile in a range of (potentially host-related) niches in soil.
We previously found that, upon physical contact with the soil fungus $L$. sp strain Karsten, a five-gene cluster in $P$. terrae strain BS001 becomes highly expressed [12]. This gene cluster was hypothesized to be involved in energy generation coupled to an oxidative stress response, with four of the five genes being highly upregulated [12]. The five-gene cluster includes an alkyl hydroperoxidase $A h p D$ family core domain containing protein, a cupin domain containing protein, a LysR family transcriptional regulator, a putative nucleosidediphosphate sugar epimerase and a conserved exported
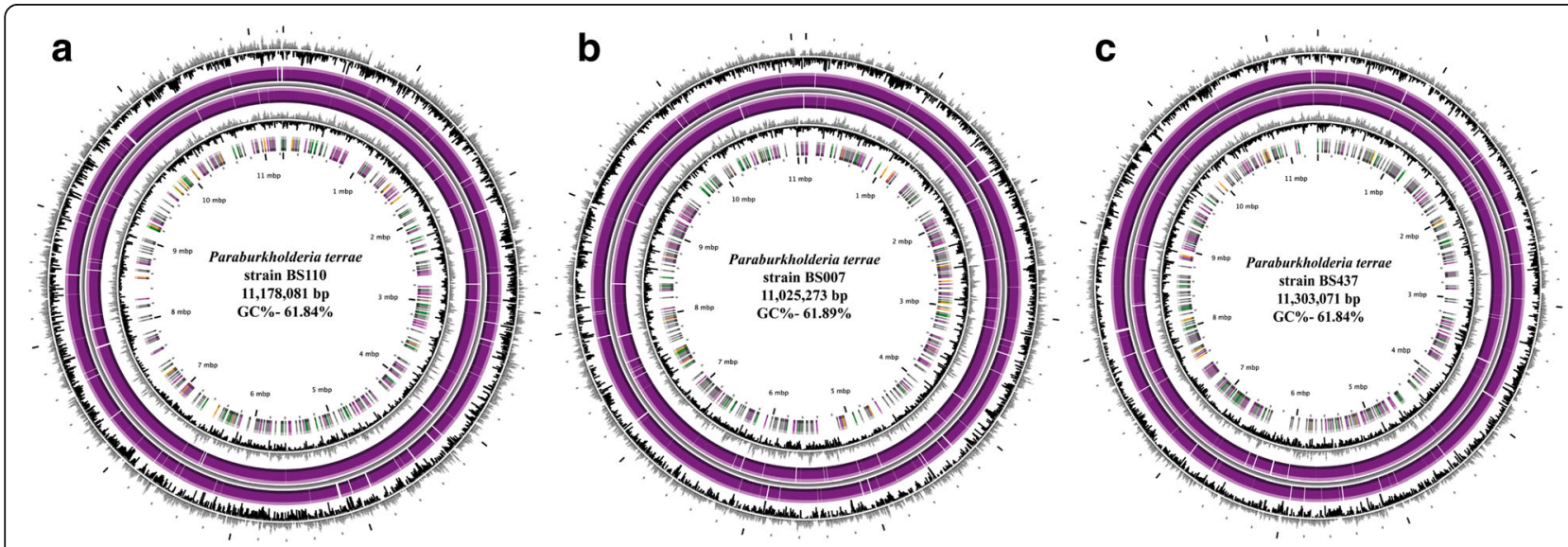

Fig. 3 Circular view of genome sequences (each consisting of several replicons) of Paraburkholderia terrae (a) strain BS110, (b) strain BS007 and (c) strain BS437. The circular display shows, from outside to inside: (i) GC percentage; (ii) Predicted CDSs transcribed in the clockwise direction; (iii) Predicted CDSs transcribed in the counterclockwise direction. (purple colour in (2) and (3) represents Primary/Automatic annotations), (iv) GC skew (G+C/G-C) and (v) color-code representing rRNA (blue), tRNA (green), miscellaneous RNA (orange), Transposable elements (pink) and pseudogenes (grey) 
Table 5 Genome statistics

\begin{tabular}{|c|c|c|c|c|c|c|}
\hline \multirow[t]{2}{*}{ Attribute } & \multicolumn{2}{|c|}{ Strain BS110 } & \multicolumn{2}{|c|}{ Strain BS007 } & \multicolumn{2}{|c|}{ Strain BS437 } \\
\hline & Value & $\%$ of total ${ }^{a}$ & Value & $\%$ of total ${ }^{a}$ & Value & $\%$ of total ${ }^{a}$ \\
\hline Genome size (bp) & $11,178,081$ & 100 & $11,025,273$ & 100 & $11,303,071$ & 100 \\
\hline Coding DNA (bp) & $9,596,382$ & 85.85 & $9,573,245$ & 86.83 & $9,724,031$ & 86.03 \\
\hline DNA G $+C$ content & $6,912,525$ & 61.84 & $6,823,541$ & 61.89 & $6,983,037$ & 61.78 \\
\hline DNA Scaffolds & 658 & - & 788 & - & 843 & - \\
\hline Total genes & 11,984 & 100 & 11,991 & 100 & 12,333 & 100 \\
\hline Protein encoding genes & 10,288 & 85.85 & 10,411 & 86.83 & 10,610 & 86.03 \\
\hline RNA genes & 54 & & 48 & & 53 & \\
\hline Pseudogenes & N/D & - & N/D & - & N/D & - \\
\hline Genes in internal clusters & N/D & - & N/D & - & N/D & - \\
\hline Genes with function prediction & 4458 & 37.2 & 4461 & 37.2 & 4743 & 38.46 \\
\hline Genes assigned to COGs & 8327 & 69.49 & 8273 & 69 & 8465 & 68.64 \\
\hline Genes assigned Pfam domains & 4015 & 33,50 & 3857 & 32.17 & 4106 & 33.29 \\
\hline Genes with signal peptides & 976 & 8.14 & 1001 & 8.35 & 1053 & 8.53 \\
\hline Genes with transmembrane helices & 1592 & 13,28 & 1555 & 12.97 & 1632 & 13.23 \\
\hline CRISPR spacers & 22 & & 21 & & 15 & \\
\hline
\end{tabular}

${ }^{a}$ The total is based on either the size of the genome in base pairs or the total number of protein encoding genes in the annotated genome; $N / D$ not determined

Table 6 Number of genes associated with general COG functional categories of Paraburkholderia terrae strain BS110, BS007, and BS437

\begin{tabular}{|c|c|c|c|c|c|c|c|}
\hline \multirow[t]{2}{*}{ Code } & \multicolumn{2}{|c|}{ Strain BS110 } & \multicolumn{2}{|c|}{ Strain BS007 } & \multicolumn{2}{|c|}{ Strain BS437 } & \multirow[t]{2}{*}{ Description } \\
\hline & Value & $\%$ of total ${ }^{a}$ & Value & $\%$ of total ${ }^{a}$ & Value & $\%$ of total ${ }^{a}$ & \\
\hline J & 242 & 2.03 & 242 & 2.03 & 253 & 2.06 & Translation, ribosomal structure and biogenesis \\
\hline A & 1 & 0.008 & 1 & 0.008 & 1 & 0.008 & RNA processing and modification \\
\hline K & 1030 & 8.65 & 1030 & 8.65 & 1026 & 8.37 & Transcription \\
\hline L & 422 & 3.54 & 422 & 3.54 & 443 & 3.61 & Replication, recombination and repair \\
\hline B & 4 & 0.03 & 4 & 0.03 & 4 & 0.03 & Chromatin structure and dynamics \\
\hline D & 68 & 0.57 & 68 & 0.57 & 69 & 0.56 & Cell cycle control, cell division, chromosome partitioning \\
\hline V & 95 & 0.79 & 95 & 0.79 & 104 & 0.84 & Defense mechanisms \\
\hline T & 573 & 4.81 & 573 & 4.8 & 605 & 4.93 & Signal transduction mechanisms \\
\hline M & 547 & 4.59 & 547 & 4.59 & 553 & 4.51 & Cell wall/membrane biogenesis \\
\hline N & 161 & 1.35 & 161 & 1.35 & 172 & 1.4 & Cell motility \\
\hline$U$ & 202 & 1.69 & 202 & 1.69 & 210 & 1.71 & Intracellular trafficking and secretion \\
\hline O & 267 & 2.24 & 267 & 2.24 & 271 & 2.21 & Posttranslational modification, protein turnover, chaperones \\
\hline C & 774 & 6.5 & 774 & 6.5 & 793 & 6.47 & Energy production and conversion \\
\hline G & 784 & 6.58 & 784 & 6.58 & 769 & 6.27 & Carbohydrate transport and metabolism \\
\hline$E$ & 1193 & 10.02 & 1193 & 10.02 & 1188 & 9.69 & Amino acid transport and metabolism \\
\hline $\mathrm{F}$ & 114 & 0.96 & 114 & 0.96 & 109 & 0.89 & Nucleotide transport and metabolism \\
\hline $\mathrm{H}$ & 263 & 2.21 & 263 & 2.21 & 268 & 2.18 & Coenzyme transport and metabolism \\
\hline । & 461 & 3.87 & 461 & 3.87 & 476 & 3.88 & Lipid transport and metabolism \\
\hline$P$ & 706 & 5.93 & 706 & 5.93 & 713 & 5.81 & Inorganic ion transport and metabolism \\
\hline Q & 387 & 3.25 & 387 & 3.25 & 395 & 3.22 & Secondary metabolite biosynthesis, transport and catabolism \\
\hline $\mathrm{R}$ & 1496 & 12.57 & 1496 & 12.57 & 1544 & 12.59 & General function prediction only \\
\hline$S$ & 682 & 5.73 & 682 & 5.73 & 703 & 5.73 & Function unknown \\
\hline W & 15 & 0.13 & 15 & 0.13 & 15 & 0.12 & Extracellular structure \\
\hline Z & 1 & 0.008 & 1 & 0.008 & 1 & 0.008 & Cytoskeleton \\
\hline
\end{tabular}




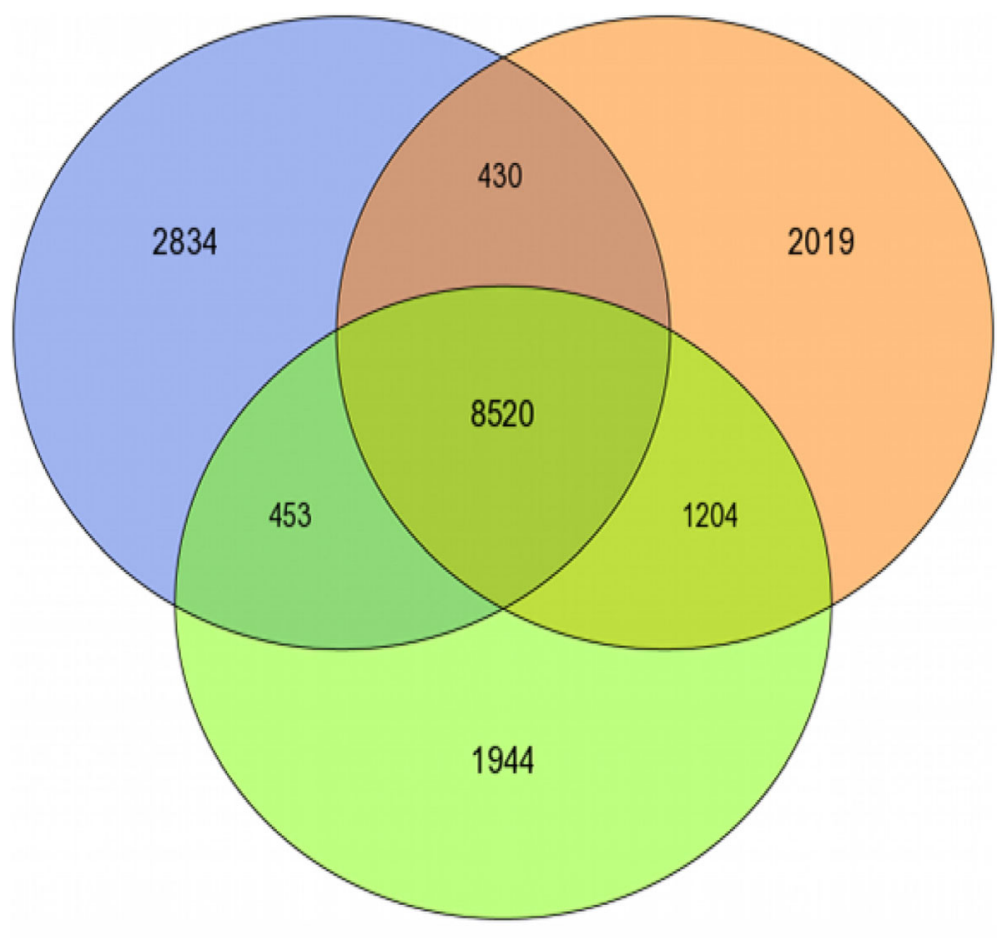

Paraburkholderia terrae BS437

Paraburkholderia terrae BS110

Paraburkholderia terrae BS007

Fig. 4 Core and pan genomes. Venn diagram analysis of Paraburkholderia terrae strain BS007, strain BS110, and strain BS437

protein of unknown function [12]. Our current genome analyses revealed that the complete gene cluster was present in all of the newly sequenced genomes (Additional file 1: Table S7). A synteny assessment of the respective clusters of the strain BS007, BS110 and BS437 genomes with that of strain BS001 showed synteny and high levels of homology across all clusters (94\%-100\%) (Fig. 7).

\section{Presence of bacteriophage-related sequences}

We finally analyzed the three genomes for the presence of prophage-like sequences, as prophages endow bacteria with traits that may advance their evolutionary fitness (following a lysogenic conversion). Thus, phenotypic plasticity of the host bacteria (i.e. with respect to virulence factors, auxiliary metabolic genes, and traits affecting biofilm formation) is fostered [21-23]. The analyses showed that the genomes of P. terrae BS110, BS007 and BS437 all contain considerable amounts of prophage-like sequences $(9.9 \%, 11.8 \%$ and $11.3 \%$, respectively), with strain BS437 being able to produce phage progeny [34].

We then analyzed the three genomes for the presence of CRISPR-Cas spacer sequences. CRISPR-Cas systems provide so-called adaptive immunity to bacteria, serving as a heritable record of past infections with phages or other extraneous elements [24]. Using the (web-based) CRISPRFinder program [25], we found CRISPR sequences to be present in all three strains; respectively

Table 7 Presumed plant- and fungal-interactive traits in Paraburkholderia terrae strain BS110, BS007, and BS437

\begin{tabular}{|c|c|c|c|c|c|c|c|c|}
\hline \multirow[t]{3}{*}{ Strain } & \multicolumn{8}{|l|}{ Traits $^{a}$} \\
\hline & \multirow[t]{2}{*}{ Plant-interactive } & \multicolumn{7}{|c|}{ Fungal-interactive } \\
\hline & & T2SS & T3SS & T4SS & T6SS & T4P & $\begin{array}{l}\text { Biofilm } \\
\text { formation }\end{array}$ & $\begin{array}{l}\text { Glycerol } \\
\text { uptake and metabolism }\end{array}$ \\
\hline BS007 & + & + & + & + & + & + & + & + \\
\hline BS110 & + & + & + & + & + & + & + & + \\
\hline BS437 & + & + & + & + & + & + & + & + \\
\hline
\end{tabular}

Indicates the presence of plant- and fungal-interactive traits; abbreviations in glossary. For more details see Additional file 1: Tables S6-S8 


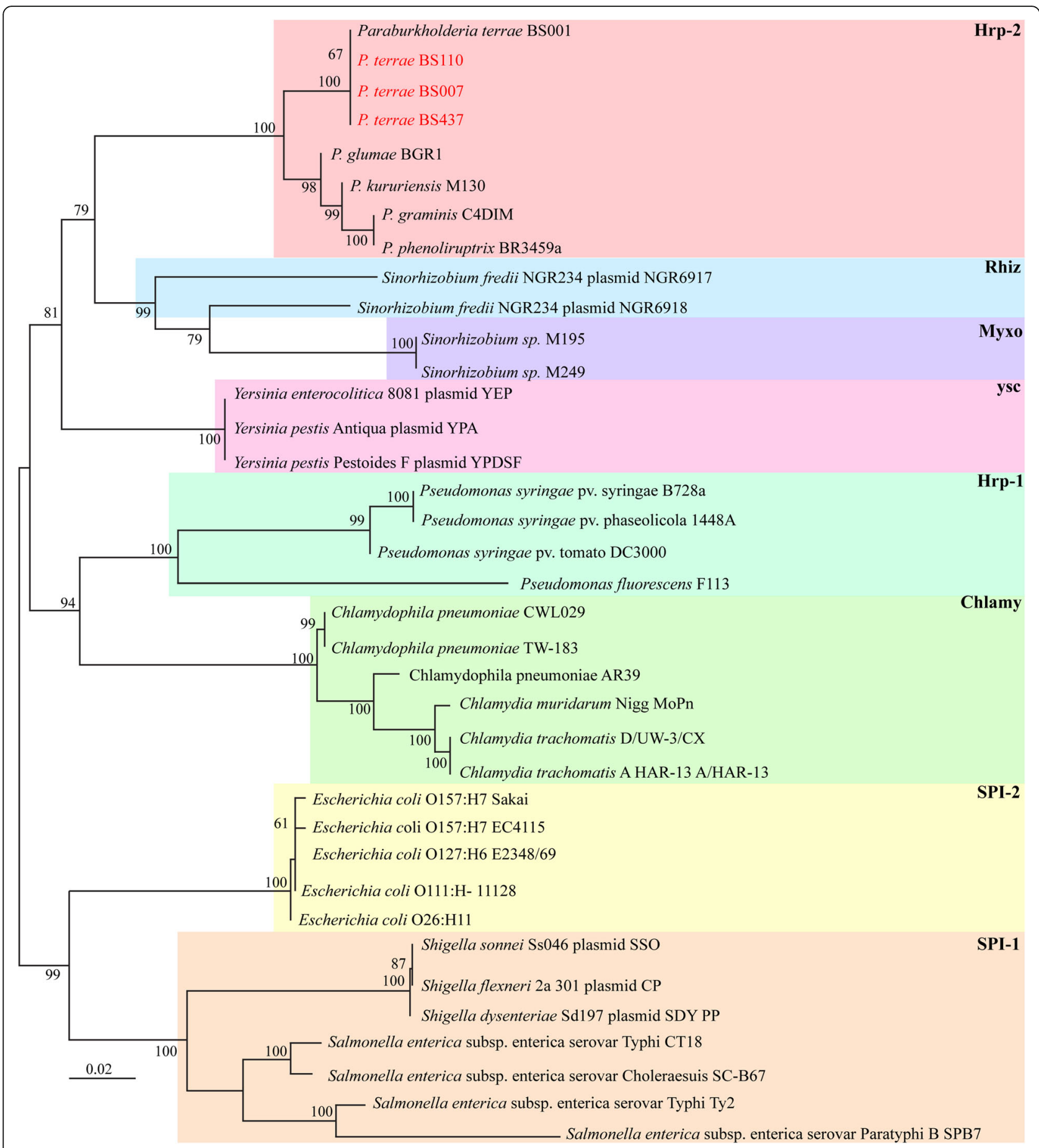

Fig. 5 Phylogenetic tree of selected type-3 secretion systems (T3SS). The tree was generated based on alignment of eight conserved genes of the T3SS (SctS, SctR, SctQ, SctV, SctU, SctJ, SctN, and SctT). Evolutionary distance was computed with MEGA7 using a maximum-likelihood method. The bootstrap values above 50\% (from 1000 replicates) are indicated at the nodes. The T3SSs of P. terrae strains BS007, BS110 and BS437 T3SS belong to the Hrp-2 type, as previously reported for BS001 [8]. Different types of T3SSs were described in Abby and Rocha [19]

21, 22 and 15 such sequences were found in strains BS007, BS110 and BS437. This finding indicated the host strains had been exposed to numerous extrachromosomal element (e.g. phage) infestations.

\section{Conclusions}

The here reported genome analyses of the fungalinteractive Paraburkholderia terrae strains BS110, BS007 and BS437 revealed that all genomes were large in size, 


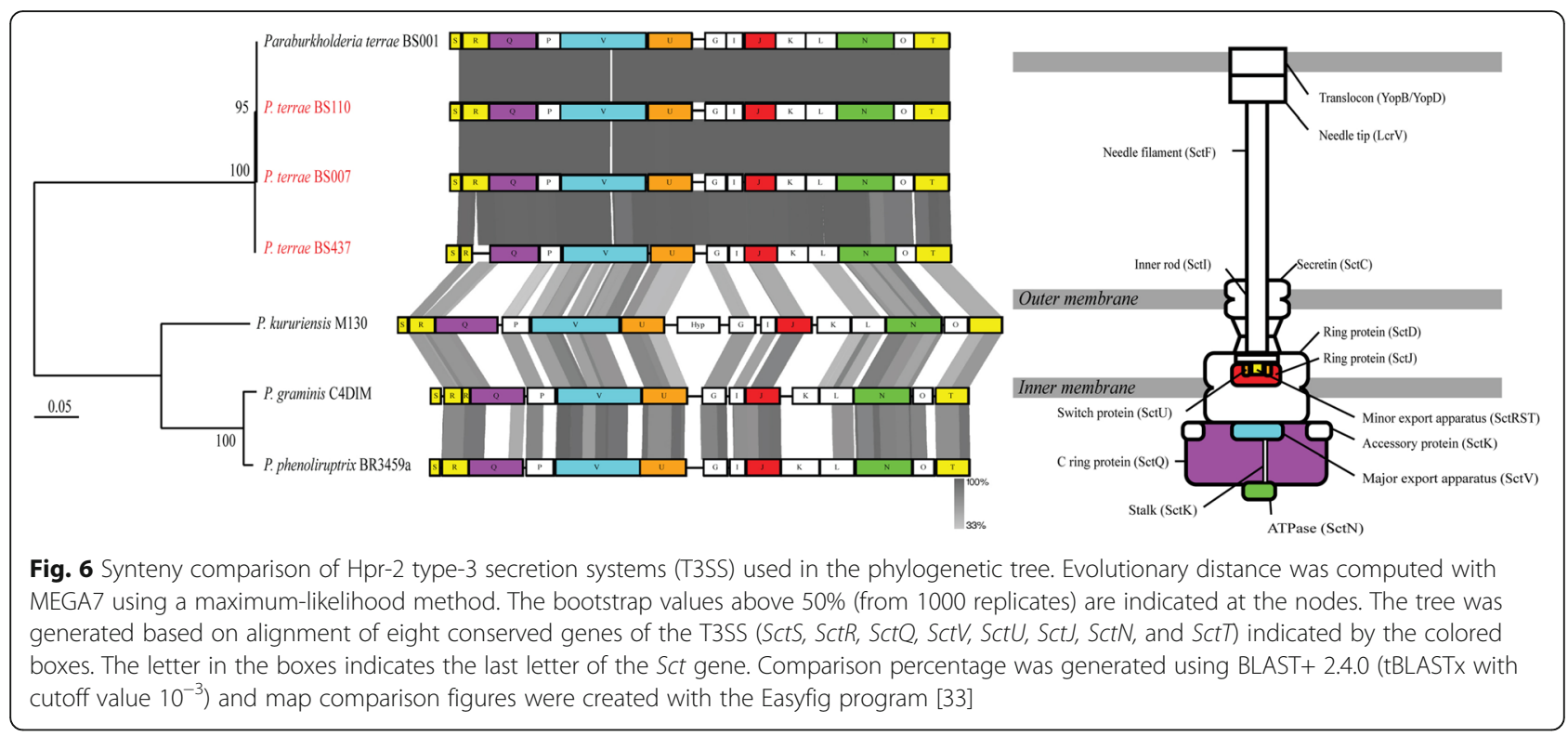

encompassing a suite of metabolic, nutrient capture and 'interactivity' genes. The repertoire of genetic systems found probably encompasses traits that allow adaptation to niches in the soil as influenced by organisms such as fungi, as well as plants. Moreover, potential defense systems were also found. Thus, all genomes harbored highly diverse primary and secondary metabolite systems. Furthermore, they also contained sets of genes for type-4 pili, biofilm formation (PGA, alginate and pel), secretion systems (T1SS, T2SS, T3SS, T4SS and T6SS) and glycerol uptake systems; such systems potentially enable them to reap the ecological benefits

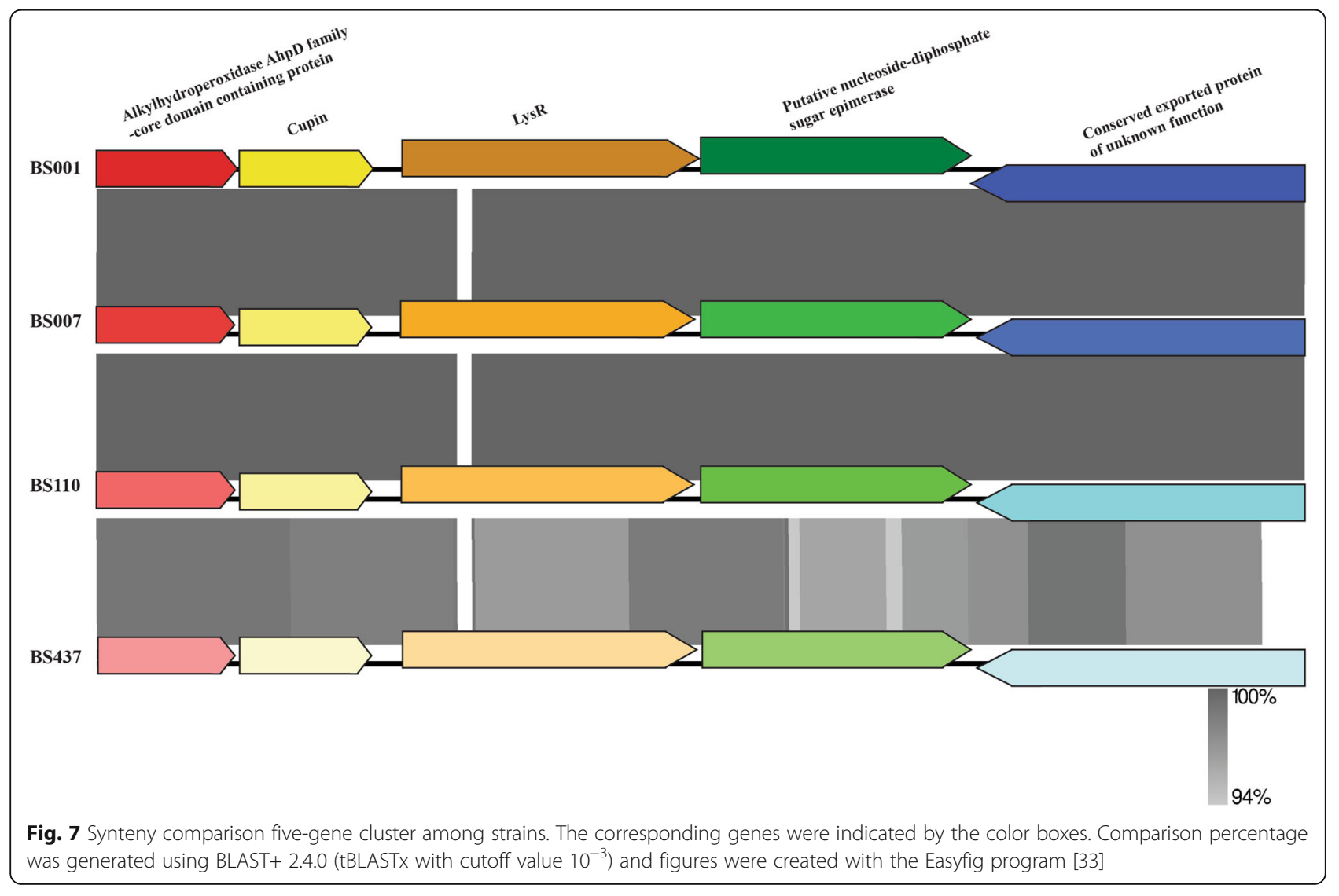


conferred by fungal hyphae in soil. A five-gene cluster, that had been found to be highly upregulated upon physical contact with Lyophyllum sp. strain Karsten in strain BS001, was consistently found in all three strains. This allowed the hypothesis that this gene cluster may confer a fitness advantage to the organisms in the early stages of contact with fungal mycelium in soil. Finally, our analyses also highlight the presence of a considerable amount of prophage-like sequences, complete or incomplete, in the $P$. terrae genomes. The significance of these prophage sequences for the host cells and their effects on the ecological functioning and adaptability of the hosts is still under investigation.

\section{Additional file}

Additional file 1: Table S1 Sequencing statistics analysis of Paraburkholderia terrae BS007, BS110, and BS437. Table S2 Pan/core genome. Table S3 Metabolic profiles of compared bacterial strains (Based on a score from 0 to 1). Table S4.1 Secondary metabolites, BSO07. Table S4.2 Secondary metabolites, BS110. Table S4.3 Secondary metabolites, BS437. Table S5.1 Nodulation genes. Table S5.2 Type 4 pili and biofilm formation systems. Table S5.3 Indole acetic acid (IAA) biosynthesis. Table S5.4 1-aminocyclopropane-1-carboxylate deaminase (ACC deaminase). Table S6.1 Type-1 secretion systems. Table S6.2 Type-2 secretion systems. Table S6.3 Type-3 secretion systems. Table S6.4 Type-4 secretion systems. Table S6.5 Type- 6 secretion systems. Table S7 Homology of putative energy-generating gene clusters to P. terrae BS001. (XLSX $164 \mathrm{~kb}$ )

\section{Abbreviations}

CRISPR: Clustered regularly interspaced short palindromic repeats; T1SS: type 1 secretion system; T2SS: type 2 secretion system; T3SS: type 3 secretion system; T4P: type 4 pili; T4SS: type 4 secretion system; T6SS: type 6 secretion system

\section{Acknowledgements}

We would like to thank the Center for Information Technology of the University of Groningen for providing access to the Peregrine high performance computing cluster.

\section{Funding}

A scholarship of the Indonesia Endowment Fund for Education (LPDPLembaga Pengelolaan Dana Pendidikan, Departemen Keuangan, Republik Indonesia) to A.A.P. Funding from the People Programme (Marie Curie Actions) of the European Union's Seventh Framework Programme FP7/20072013/ under REA grant agreement n 607,786, BluePharmTrain to M.C.D.M.

\section{Authors' contributions}

Conceived the project: RN, JDVE. Performed the research: RN, IUH, AAP. Analyzed and interpreted results: AAP, IUH, MCDM, JDVE. Wrote the manuscript: AAP, IUH, JDVE. All authors read and approved of the manuscript and none of the authors have any competing interests regarding the manuscript.

\section{Competing interests}

The authors declare that they have no competing interests.

\section{Publisher's Note}

Springer Nature remains neutral with regard to jurisdictional claims in published maps and institutional affiliations.

\section{Author details}

${ }^{1}$ Department of Microbial Ecology, Microbial Ecology - Groningen Institute for Evolutionary Life Sciences, University of Groningen, Nijenborgh 7, Groningen 9747, AG, The Netherlands. ${ }^{2}$ Department of Environmental Sciences COMSATS Institute of Information Technology, University Road, Abbottabad 22060, Pakistan.
Received: 2 June 2017 Accepted: 24 November 2017

Published online: 18 December 2017

\section{References}

1. Yabuuchi E, Kosako Y, Oyaizu H, Yano I, Hotta H, Hashimoto Y, et al. To the new genus, with the type species Burkholderia. Microbiol Immunol. 1992;40:1251-75.

2. Estrada-De Los Santos P, Vinuesa P, Martinez-Aguilar L, Hirsch AM, Caballero-Mellado J. Phylogenetic analysis of Burkholderia species by multilocus sequence analysis. Curr Microbiol. 2013:67:51-60.

3. Sawana A, Adeolu M, Gupta RS. Molecular signatures and phylogenomic analysis of the genus Burkholderia: proposal for division of this genus into the emended genus Burkholderia containing pathogenic organisms and a new genus Paraburkholderia gen. Nov. harboring environmental species. Front Genet. 2014;5:1-22.

4. Salles JF, Souza FA. De, Elsas JD van. Molecular method to assess the diversity of of Burkholderia species in environmental samples. Appl Environ Microbiol. 2002;68:1595-603.

5. Nazir R, Zhang M, de Boer W, van Elsas JD. The capacity to comigrate with Lyophyllum sp. strain Karsten through different soils is spread among several phylogenetic groups within the genus Burkholderia. Soil Biol Biochem. 2012;50: 221-33. Available from: https://doi.org/10.1016/j.soilbio.2012.03.015

6. Sahl JW, Allender CJ, Colman RE, Califf KJ, Schupp JM, Currie BJ, et al. Genomic characterization of Burkholderia pseudomallei isolates selected for medical countermeasures testing: comparative genomics associated with differential virulence. PLoS One. 2015;10:1-18.

7. Compant S, Nowak J, Coenye T, Clément C, Ait Barka E. Diversity and occurrence of Burkholderia spp. in the natural environment. FEMS Microbiol Rev. 2008;32:607-26.

8. Haq IU, Graupner K, Nazir R, van Elsas JD. The genome of the fungalinteractive soil bacterium Burkholderia terrae BS001-a plethora of outstanding interactive capabilities unveiled. Genome Biol Evol. 2014;6: 1652-68.

9. Warmink JA, van Elsas JD. Selection of bacterial populations in the mycosphere of Laccaria proxima: is type III secretion involved? ISME J. 2008; 2:887-900. Available from: http://www.nature.com/doifinder/10.1038/ismej. 2008.41

10. Haq IU, da Rocha Calixto RO, Yang P, GMP DS, Barreto-Bergter E, van Elsas JD. Chemotaxis and adherence to fungal surfaces are key components of the behavioral response of Burkholderia terrae BS001 to two selected soil fungi. FEMS Microbiol Ecol. 2016;92:1-14.

11. Yang $P$, Zhang $M$, Warmink JA, Wang $M$, van Elsas JD. The type three secretion system facilitates migration of Burkholderia terrae BS001 in the mycosphere of two soil-borne fungi. Biol Fertil Soils. 2016;52:1037-1046. Available from:. https://doi.org/10.1007/s00374-016-1140-6.

12. Haq IU, Dini-Andreote F, van Elsas JD. Transcriptional responses of the bacterium Burkholderia terrae BS001 to the fungal host Lyophyllum sp. strain karsten under soil-mimicking conditions. Microb Ecol. 2017;73:236-252. Available from: https://doi.org/10.1007/s00248-016-0885-7.

13. Vallenet D, Belda E, Calteau A, Cruveiller S, Engelen S, Lajus A, et al. MicroScope - an integrated microbial resource for the curation and comparative analysis of genomic and metabolic data. Nucleic Acids Res. 2013;41:636-47.

14. Yang $\mathrm{P}$, Zhang M, van Elsas JD. Role of flagella and type four pili in the comigration of Burkholderia terrae BS001 with fungal hyphae through soil. Sci Rep. 2017;7:2997. Available from: http://www.nature.com/articles/s41598017-02959-8

15. Shi W, Sun H, Type IV. Pilus-dependent motility and its possible role in bacterial pathogenesis. Society. 2002;70:1-4.

16. Yakandawala N, Gawande PV, LoVetri K, Cardona ST, Romeo T, Nitz M, et al. Characterization of the poly- $\beta-1,6-\mathrm{N}$-acetylglucosamine polysaccharide component of Burkholderia biofilms. Appl Environ Microbiol. 2011;77:8303-9.

17. Schurr MJ. Which bacterial biofilm exopolysaccharide is preferred, psl or alginate? J Bacteriol. 2013;195:1623-6.

18. Colvin KM, Gordon VD, Murakami K, Borlee BR, Wozniak DJ, Wong GCL, et al The pel polysaccharide can serve a structural and protective role in the biofilm matrix of Pseudomonas aeruginosa. PLoS Pathog. 2011;7

19. Abby SS, Rocha EPC. The non-flagellar type III secretion system evolved from the bacterial flagellum and diversified into host-cell adapted systems. PLoS Genet. 2012;8

20. Lackner G, Moebius N, Hertweck C. Endofungal bacterium controls its host by an hrp type III secretion system. ISME J. 2011;5:252-61. Available from: http://www.nature.com/doifinder/10.1038/ismej.2010.126 
21. Brüssow H, Canchaya C, Hardt W, Bru H. Phages and the evolution of bacterial pathogens : from genomic rearrangements to lysogenic conversion phages and the evolution of bacterial pathogens : from genomic rearrangements to lysogenic conversion. Microbiol Mol Biol Rev. 2004;68:560-602.

22. Breitbart M. Marine viruses: truth or dare. Annu Rev Mar Sci. 2012;4:425-48. Available from: http://www.annualreviews.org/doi/10.1146/annurev-marine120709-142805

23. Obeng N, Pratama AA, van Elsas JD. The significance of mutualistic phages for bacterial ecology and evolution. Trends Microbiol. 2016;24:440-449. Available from:. https://doi.org/10.1016/j.tim.2015.12.009.

24. Marraffini LA, Sontheimer EJ. CRISPR interference: RNA-directed adaptive immunity in bacteria and archaea. Nat Rev Genet. 2011;11:181-90.

25. Grissa I, Vergnaud G, Pourcel C. CRISPRFinder: a website to compare clustered regularly interspaced short palindromic repeats. Nucleic Acids Res. 2008;36:52-7.

26. Field D, Garrity G, Gray T, Morrison N, Selengut J, Sterk P, et al. The minimum information about a genome sequences (MIGS) specification. Nat Biotechnol. 2008;26:541-7.

27. Woese CR, Kandler O, Wheelis ML. Towards a natural system of organisms: proposal for the domains archaea, bacteria, and Eucarya. Proc Natl Acad Sci. 1990; 87:4576-9. Available from: http://www.pnas.org/cgi/doi/10.1073/pnas.87.12.4576

28. Garrity GM, Bell JALT, Phylum X. Proteobacteria phyl nov. In: Garrity GM, Brenner DJ, SJ KNR, editors. Bergey's man. Sytematic Bacteriol. Vol. 2. 2nd ed. New York: Springer US; 2005.

29. Garrity GM, Bell JALT, Class II. Betaproteobacteria class. Nov. In: Garrity GM, Brenner DJ, SJ KNR, editors. Bergey's man. Syst. Bacteriol. Vol.2. 2nd ed. New York: Springer US; 2005.

30. Garrity GM, LT BJA, Order I. Burkholderiales ord. nov. In: Garrity GM, Brenner DJ, SJ KNR, editors. Bergey's Man. Syst. Bacteriol. Vol.2. 2nd ed. New York: Springer US; 2005. p. 575.

31. Garrity GM, LT BJA, Family I. Burkholderiaceae fam. nov. In: Garrity GM, Brenner DJ, SJ KNR, editors. Bergey's Man. Sytematic Bacteriol. Vol. 2. 2nd ed. New York: Springer US; 2005. p. 575.

32. Nazir R, Hansen MA, Sørensen S, van Elsas JD. Draft genome sequence of the soil bacterium Burkholderia terrae strain BS001, which interacts with fungal surface structures. J Bacteriol. 2012;194:4480-1.

33. Sullivan MJ, Petty NK, Beatson SA. Easyfig: A genome comparison visualizer. Bioinformatics. 2011;27:1009-10.

34. Pratama AA and van Elsas JD. A novel inducible prophage from the mycosphere inhabitant Paraburkholderia terrae BS437. Sci. Rep. ;2017;7:9156. Available from: http:/www.nature.com/articles/s41598-017-09317-8

\section{Submit your next manuscript to BioMed Central and we will help you at every step:}

- We accept pre-submission inquiries

- Our selector tool helps you to find the most relevant journal

- We provide round the clock customer support

- Convenient online submission

- Thorough peer review

- Inclusion in PubMed and all major indexing services

- Maximum visibility for your research

Submit your manuscript at www.biomedcentral.com/submit 